|| ISSN(online): 2589-8698 || ISSN(print): 2589-868X || International Journal of Medical and Biomedical Studies

Available Online at www.ijmbs.info

PubMed (National Library of Medicine ID: 101738825)

Index Copernicus Value 2017: 40.03

Volume 3, Issue 3; March: 2019; Page No. 52-57

\title{
PREDICTION VALUE OF OXYGENATION INDEX AS PREDICTOR FOR POSTOPERATIVE PULMONARY COMPLICATIONS IN UROLOGIC SURGERY
}

\section{Maja Mojsova Mijovska ${ }^{1}$, Aleksandra Gavrilovska-Brzanov ${ }^{1}$, Marija Jovanovski Srceva $^{1}$, Zuzanne Ehmer Nelepa ${ }^{2}$, Nikola Brzanov ${ }^{1}$}

${ }^{1}$ University Clinic for Traumatology, Orthopedic disease, Anesthesiology, Reanimation and Intensive Care Medicine and Emergency department, Faculty of Medicine, University "Ss. Cyril and Methodius", Skopje, R. Macedonia

${ }^{2}$ DHA Rashid Hospital Dubai UAE

Article Info: Received 10 February 2019; Accepted 05 March. 2019

Cite this article as: Mijovska, M., Brzanov, A., Srceva, M., Nelepa, Z., \& Brzanov, N. (2019). PREDICTION VALUE OF OXYGENATION INDEX AS PREDICTOR FOR POSTOPERATIVE PULMONARY COMPLICATIONS IN UROLOGIC SURGERY. International Journal of Medical and Biomedical Studies, 3(3).

DOI: https://doi.org/10.32553/ijmbs.v3i3.125

Address for Correspondence: Aleksandra Gavrilovska-Brzanov, ${ }^{1}$ University Clinic for Traumatology, Orthopedic disease, Anesthesiology, Reanimation and Intensive Care Medicine and Emergency department, Faculty of Medicine, University "Ss. Cyril and Methodius", Skopje, R. Macedonia

Conflict of interest: No conflict of interest.

\section{Abstract}

Introduction: It is believed that pressure/flow (P/F) ratio (arterial oxygen to inspired oxygen fraction) does not give the best expression of oxygenation status in mechanically ventilated patients. Therefore, a new oxygenation index (OI) where the mean airway pressure (MAP) is incorporated $\left(\mathrm{PaO}_{2} / \mathrm{FiOxMAP}\right)$ is showed as superior to $P / F$ in expression of the lung oxygenation status. In this article we wanted to assess the prediction value of $\mathrm{Ol}$ calculated during urological surgeries as a predictive marker for developing postoperative pulmonary complications (PPC).

Material and methods: We evaluated all elective urologic patients operated in general endotracheal anesthesia, aged 18 to 65 years, without any known history of respiratory disease for the period from January till December 2017. We calculated the $P / F$ ratio and the $O$ at three time points: after induction in general endotracheal anesthesia in the beginning of mechanical ventilation, 1 hour after induction in anesthesia, and at the end of the surgery before weaning the mechanical ventilation. The primary outcomes were PPC defined by European Society of Anesthesia. The second outcomes were: length of hospital stay, admission to intensive care unit (ICU) and mortality.

Results: A total of 240 patients who met the inclusion criteria were included in this evaluation and finally analyzed. PPC were diagnosed in $25 \%$ of patients and respectively $75 \%$ were without complications. Postoperative hospital stay was longer in PPC group no matter they were operated laparoscopically or with classic open surgery (PPC laparoscopy $4.9 \pm 2.2$ vs. non PPC laparoscopy $3.3 \pm$ 1.7, PPC laparotomy $6.8 \pm 5.2$ vs. non PPC $5.6 \pm 2.1$ laparotomy). Ten patients were admitted to ICU, 8 from PPC group and 2 from non PPC group. In PPC group patients were admitted to ICU for mean $3.7 \pm$ 2.4 days, and in non PPC group patients were hospitalized in ICU only for 2 days. All evaluated patients were discharged from the hospital and no mortality was observed in the 30 postoperative days. 
In the univariate and multivariate logistic regression analysis neither OI nor P/F were significantly associated with PPC.

Conclusion: This study does not offer a conclusive answer to the prediction value of OI for PPC. It would be fruitful to pursue further research about predictive variables for pulmonary complications.

Keywords: oxygenation index, pressure/flow ratio, mean airway pressure, postoperative pulmonary complications.

\section{Introduction:}

Postoperative pulmonary complications (PPC) are still one of the major cause of postoperative mortality. Incidences of PPC are reported as high in the elderly population requiring urological intervention due to increased preexisting comorbidities $(1,2)$. Identifying patients with an increased risk of development of PPC can lead to improved preoperative evaluation, perioperative management and postoperative therapy. Risk factors for PPC can be classified into patientsrelated and surgery-related risk factors (3).

Ventilation specific parameters are also used to predict PPC. In the article of Chan et al. (4) plateau pressure is reported as an independent risk of hospital mortality. The pressure/flow (P/F) ratio known as arterial oxygen to inspired oxygen fraction is widely used to determine the prognostic outcome of patients with acute respiratory distress syndrome (ARDS) and acute lung injury (ALI)/ acute respiratory insufficiency (ARI). However, nowadays it is believed that $P / F$ ratio does not give the best expression of oxygenation status and a new oxygenation index where the mean airway pressure (MAP) is incorporated $\left(\mathrm{PaO}_{2} / \mathrm{FiOxMAP}\right)$ and has been shown superior to $P / F$ in mechanically ventilated (MV) patients, for expression of the intrapulmonary shunting and lung oxygenation status (5).

Oxygenation index (OI) is defined as reciprocal of the $\mathrm{P} / \mathrm{F}$ ratio multiplied by the MAP. OI is widely used in ICU as an index for the gravity of lung injury in both children and adults (6). OI has been also evaluated in the thoracic surgery demanding one-lung ventilation (OLV) (7). However, we have not found any report in the literature for on evaluation of the $\mathrm{Ol}$ as a predictive factor in the non-thoracic everyday surgical practice.
The aim of this study was to assess the prediction potency of $\mathrm{Ol}$ calculated during urological surgeries as a predictive marker for developing PPC.

\section{Material and methods}

\section{Data sources}

We conducted this evaluation in the tertiary University Clinical Hospital "Mother Theresa" Skopje, at the Department of anesthesia, reanimation and intensive care and at the Urology department for the period from January till December 2017. All patients that underwent elective urological intervention under general endotracheal anesthesia, ASA I/II, aged 18 to 65 years, without any known history of respiratory disease were included in this evaluation. We excluded pregnant patients, patients with known respiratory disease, transplanted patients.

Investigated parameters in three phases

Investigated parameters were collected at three time points: after induction in general endotracheal anesthesia at the beginning of mechanical ventilation, 1 hour after induction in anesthesia, and at the end of the surgery before weaning the mechanical ventilation.

\section{Parameter's determination}

We evaluated demographic characteristics, operative diagnosis and parameters obtained from the arterial blood gases analyses $\left(\mathrm{PaO}_{2}\right.$, $\mathrm{PCO}_{2}, \mathrm{SaO}_{2}$ ); we calculated the $\mathrm{P} / \mathrm{F}$ ratio and the Ol at all three time points.

Ol was calculated as reciprocal of the $\mathrm{P} / \mathrm{F}$ ratio multiplied by MAP. The $\mathrm{PaO}_{2}$ obtained by the arterial gas analyses, fraction of inspired oxygen concentration and ventilator determinate MAP were used to calculate the OI. 


\section{Outcome definitions}

The primary outcomes were PPC defined by European Society of Anesthesia (8): persistent coughing $>15$ seconds, new detection of respiratory wheezing treated with bronchodilators, pulmonary embolism, reintubation, respiratory insufficiency, atelectasis, pneumothorax, aspiration pneumonia, pneumonia, pleural effusion, bronchospasm, laryngospasm, acute respiratory distress syndrome (ARDS). PPC were assessed within the first 30 days postoperatively in post-anesthesia care unit and in the ward during the entire time of patients' hospitalization. The second outcomes were: length of hospital stay, admission to ICU and mortality.

\section{Statistical analysis}

A computer database was created and analysis was performed with IBM SPSS (20.0) program. Descriptive and analytical standard methods were used. The odds relations, measures of the central tendency or proportions were used for analysis of the numerical and attributive data. They were reported as median and ranges and categorical variables were expressed in percentage. Statistical significance was indicated when $\mathrm{p}$ was $<0.05$ tested with analysis of variance and difference.

\section{Results}

Between January and December 2017, a total of 1517 cases were evaluate in the tertiary University Clinical Hospital "Mother Theresa" Skopje, at the Department for anesthesia, reanimation and intensive care and at the Urology department. A total of 1017 of them received regional or local anesthesia and were excluded from the evaluation. 175 patients did not meet the inclusion criteria. Forty-five patients were excluded from the evaluation since arterial blood gas analysis during surgery was not performed. Additionally 40 cases were excluded due to missing data.

A total of 240 patients who met the inclusion criteria were included in this evaluation and analyzed. Sixty-six of them underwent prostatectomy, 90 patients underwent nephrectomy, 11 patients underwent renal cyst removal, 15 patients had suprarenal gland removal, 14 patients had varicocele and 44 patients underwent Bricker procedure (urinary ileostomy).
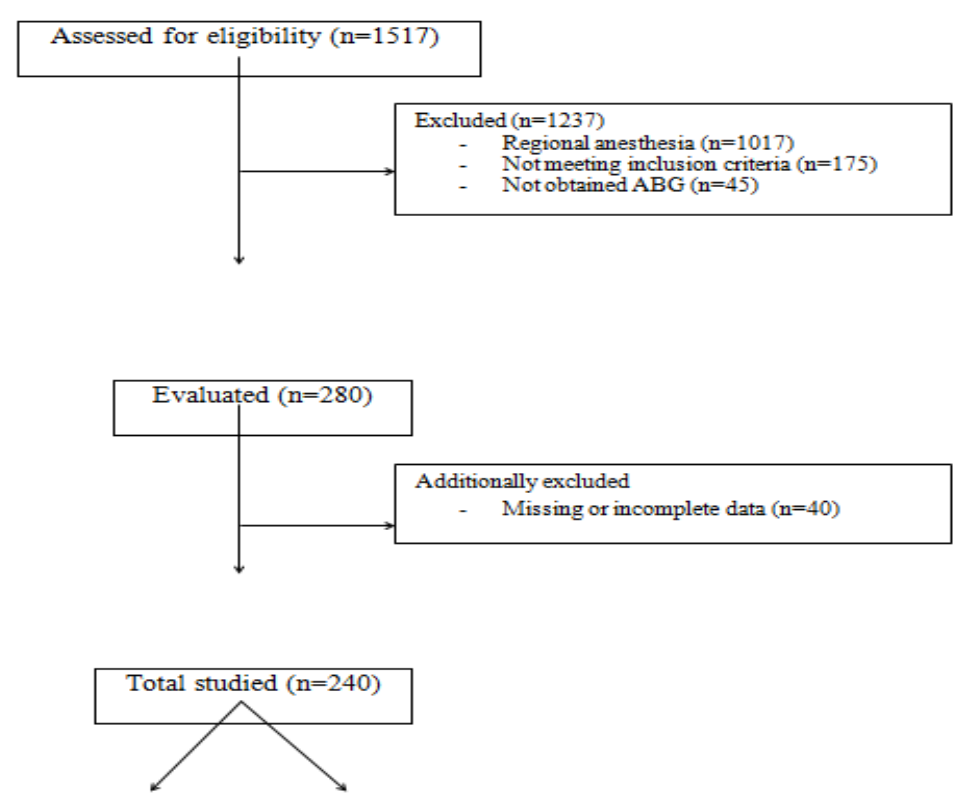

PPC $(n=60)$

non - PPC $(n=180)$

Figure 1: Study participants flow diagram 
Table 1: Patients and surgery characteristics

\begin{tabular}{|l|l|l|}
\hline Variables & PPC & non-PPC \\
\hline Age $(\mathrm{y})$ & $50.2 \pm 12.84$ & $49.93 \pm 13.99$ \\
\hline Sex M/F & $58 / 12$ & $120 / 60$ \\
\hline ASA I/II & $10 / 50$ & $70 / 110$ \\
\hline BMI & $25.84 \pm 3.5$ & $25.92 \pm 2.76$ \\
\hline Surgery Open / Laparoscopic & $35 / 25$ & $77 / 103$ \\
\hline Anesthesia time & $215 \pm 86,54$ & $233 \pm 80.00$ \\
\hline Surgery time & $176.8 \pm 77.24$ & $193.2 \pm 76.30$ \\
\hline
\end{tabular}

Data presented as mean and SD, ASA - physical status classification system, BMI - body mass index, PPC -postoperative pulmonary complications.

PPC were diagnosed in $25 \%$ of patients and respectively $75 \%$ were without complications. There were 185 measurements of $\mathrm{Ol}$ in PPC group and 550 in non PPC group. Postoperative hospital stay was longer in PPC group no matter they were operated laparoscopically or with classic open surgery (PPC laparoscopy $4.9 \pm 2.2$ vs. non PPC laparoscopy $3.3 \pm 1.7$, PPC laparotomy $6.8 \pm 5.2$ vs. non PPC $5.6 \pm 2.1$ laparotomy ) $(p<0.005)$. Ten patients were admitted to ICU 10, 8 from PPC group and 2 from non PPC group. In PPC group patients were admitted to ICU for mean $3.7 \pm 2.4$ days, and in non PPC group patients were hospitalized in ICU for 2 days. All evaluated patients were discharged from the hospital and no mortality was observed in the 30 postoperative days.

Table 2: OI and $\mathrm{P} / \mathrm{F}$ ratio

\begin{tabular}{|l|l|l|}
\hline & OI & $\mathrm{P} / \mathrm{F}$ \\
\hline PPC & $5.9 \pm 1.31(\min 4.4 / \max 9.02)$ & $170.9 \pm 13.70(\min 139 / \max 202)$ \\
\hline non PPC & $4.7 \pm 1.06(\min 3.3 / \max 7.4)$ & $190 \pm 14.12(\min 154 / \max 210)$ \\
\hline P value & $\mathrm{P}<0.005$ & $\mathrm{P}<0.05$ \\
\hline
\end{tabular}

Data presented as mean and SD, min - minimum, max - maximum, Ol -oxygenation index, $\mathrm{P} / \mathrm{F}$ partial pressure of oxygen/inspired oxygen fraction.

In the univariate and multivariate logistic regression analysis neither $\mathrm{Ol}$ nor $\mathrm{P} / \mathrm{F}$ were significantly associated with PPC. However, according to Spearman Rank Order Correlations test we registered a statistically significantly moderate positive correlation between $\mathrm{P} / \mathrm{F}$ ratio and PPC, and a strong statistically significantly negative correlation between $\mathrm{Ol}$ and PPC.

Table 3: Ventilation parameters

\begin{tabular}{|l|l|l|l|}
\hline Variables & PPC & non-PPC & P value \\
\hline $\mathrm{MV}(\mathrm{L} / \mathrm{min})$ & $5 \pm 1$ & $5 \pm 1$ & $\mathrm{p}>0.05$ \\
\hline PPEP & $5 \pm 1$ & $5 \pm 1$ & $\mathrm{p}>0.05$ \\
\hline $\mathrm{Vt}(\mathrm{ml})$ & $400 \pm 65$ & $415 \pm 76$ & $\mathrm{p}>0.05$ \\
\hline Peak pressure & $19 \pm 10$ & $18 \pm 9$ & $\mathrm{p}>0.05$ \\
\hline Plato pressure $\left(\mathrm{cmH}_{2} \mathrm{O}\right)$ & $15 \pm 5$ & $15 \pm 4$ & $\mathrm{p}>0.05$ \\
\hline $\mathrm{EtCO}_{2}\left(\mathrm{cmH}_{2} \mathrm{O}\right)$ & $40 \pm 7$ & $39 \pm 7$ & $\mathrm{P}>0.05$ \\
\hline
\end{tabular}

Data presented as mean and $\mathrm{SD}, \mathrm{MV}$-minute ventilation, PPC -postoperative pulmonary complications, $\mathrm{Vt}$ - tidal volume, PEEP - positive end expiratory pressure, $\mathrm{EtCO}_{2}$ - end tidal carbon dioxide. 


\section{Discussion}

We believe that $P / F$ ratio might not be the most excellent impression of oxygenation status in MV patients. Therefore, we wanted to evaluate the prediction value of OI where MAP shows better reflection in the oxygenation status for identification of patients who are at risk of developing PPC. By incorporating MAP in P/F equation we can have superior impression of the lung functional status. In this evaluation we found no significant association of $\mathrm{Ol}$ with the development of PPC. A slightly decreased OI was observed in PPC group (non PPC $4.7 \pm 1.06$ vs. PPC $5.9 \pm 1.31$ ), however, there was no statistically significant difference between non PPC and PPC group ( $p>0.05$ ).

We assume that maybe due to the fact that our patients were elective cases with relatively brief duration of mechanical ventilation, we did not identify OI as a predictor for PPC. However, some studies in the literature, such as the cohort study of 259 patients analyzed by Monchi et al. reported $\mathrm{Ol}$ to be a valuable predictor for mortality in ARDS patients (9). Another derivation cohort from Go et al., analyzed data from 3 ARDSNet studies, ARMA, FACTT, and ALVEOLI, as well as data from the ARDS et Curarisation Systematique (ACURASYS) study and although they did not demonstrate the usefulness of $\mathrm{OI}$ in individual patients with ARDS, they presented the importance of $\mathrm{Ol}$ in distinguishing patients with and without response to intervention (10). Modified OI with age for predicting mortality in patients with ARDS was developed by Dechert et al. using the ARDSNet database. They detected that Ol modified with age had AUC of 0.70 to 0.74 for the first four days of predicting mortality. Seeley et al. (11) in their univariate and multivariate analysis identified $\mathrm{OI}$ as a superior independent predictor of mortality compared to $\mathrm{P} / \mathrm{F}$; they assumed that maybe due to the integrated MAP and oxygenation into a distinct variable, OI was the determinant that stayed significant for mortality prediction.
Development of Ol was associated with extracorporeal membrane oxygenation (ECMO), and higher $\mathrm{Ol}$ correlated with greater need for ECMO in the study of Bayrakci et al. (12). Another study enrolled pediatric patients with respiratory failure aged 1 month to 18 years, and identified higher OI as independently associated with mortality without extubation (6).

Despite the fact that $P / F$ remains essential for diagnosis of ADRS, according to the American European Consensus Conference, value of $<300$ $P / F$ has been defined as an acute lung injury. Revised in the Berlin definition, PEEP has been included in $\mathrm{P} / \mathrm{F}$ ratio for graduating the severity of ARDS (13), however Ol still has a superior predictive value.

Ol is a composite index that indicates gas exchange of the lungs and compliance of the lungs (14). Another study that evaluated $\mathrm{OI}$ in everyday clinical practice had comprised patients who underwent thoracic surgery demanding OLV (7). The authors evaluated and analyzed 296 patients and did not isolate $\mathrm{Ol}$ as a predictor for PPC. However, they used a non-controlled mode of ventilation which may have impact on the parameters incorporated in the Ol equation.

The limitations of our study are the retrospective and single center design as well as the relatively small sample size. The relatively healthy patients ASA I/II, leave the Ol unanswered in more complicated patients. On the other hand, we used mean data rather than worst Ol which can lead to underestimation of the severity of the lung injury.

\section{Conclusion}

While this study does not offer a conclusive answer to the prediction value of Ol, it does open the door to further prospective researches including larger cohort of patients in order to determine $\mathrm{Ol}$ as a predictor for PPC and to determine the predictive variables for pulmonary complications. 


\section{References:}

1. Warner DO. Preventing postoperative pulmonary complications. Anesthesiology 2000;92:1467-1472.

2. Canet J, Hardman J, Sabaté $S$, et al. PERISCOPE study: predicting post-operative pulmonary complications in Europe. Eur J Anaesthesiol 2011;28:459-461.

3. Gavrilovska-Brzanov A., Slaninka Miceska M., Shosholcheva M., Kuzmanovska B., Kartalov A., Mojsova-Mijovska M., Jovanovski-Srceva M., Simeonov R., Brzanov N.. "Carboxyhemoglobin and Methemoglobin as Markers of Postoperative Pulmonary Complications". Journal of Anesthesia and Surgery 2018 May; 5(1): 61- 67. doi: 10.15436/2377-1364.18.1828.

4. Chan MC., Tseng JS., Hsu KH., Shin SJ., Yi CY., et al. Prognostic value of plateau pressure below $30 \mathrm{cmH}_{2} \mathrm{O}$ in septic subjects with acute respiratory failure. Respir Care 20155;60:12-20.

5. El-Khatib M., Jamaleddine G. Anew oxygenation index for reflecting intrapulmonary shunting in patients undergoing open heart surgery. Chest. 2004; 125:592-596. doi:10.1378/chest.125.2.592

6. Trachsel D., McCrindle BW., Nakagawa S., Bohn D., et al. Oxygenation index predicts outcome in children with acute hypoxemic respiratory failure. Am J Respir Crit Care Med 2005;172:206-211.

7. 7. Naik BI., Colquhoun DA., Shields IA., Davenport RE., Durieux ME., Blank RS. Value of the oxygenation index during 1-lung ventilation for predicting respiratory complications after thoracic surgery. J Crit
Care. 2017;37:80-84. doi: 10.1016/ j.jcrc. 2016.09.001

8. Jammer, I., Wickboldt, N., Sander, M., et al. Standards for definitions and use of outcome measures for clinical effectiveness research in perioperative medicine: European Perioperative Clinical Outcome (EPCO) definitions. (2015) Eur J Anaesthesiol 32(2): 88-105.

9. Monchi M., Bellenfant F., Cariou A., Joly LM., Thebert D., Laurent I., et al. Early predictive factors of survival in the acute respiratory distress syndrome. Amultivariate analysis. Am J Respir Critical Care Med 1998;158: 1076-1081.

10. Go L., Budinger G., Kwasny M., Peng J., Forel J., Papazian L., and Jain M. Failure to Improve the Oxygenation Index is a Useful predictor of Therapy Failure in ARDS Clinical Trials. Crit Care Med. 2016 Jan; 44(1): e40e 44. doi:10.1097/CCM.0000000000001295

11. Seeley E., McAuley DF., Eisner M., Miletin M., Matthay MA., Kallet RH. Predictors of mortality in acute lung injury during the era of lung protective ventilation. Thorax 2008;63:994-998.

12. Bayrakci B., Josephson C., Fackler J. Oxygenation index for extracorporeal membrane oxygenation: is there predictive significance? J Artif Organs 2007;0:6-9.

13. Feguson ND., Fan E., Camporota L., et al. The Berlin definition of ARDS: an expanded rationale, justification, and supplementary material. Intensiva Care Med 2012;38:15731582.

14. El-Khatib M., Jamaleddine G. Clinical relevance of the $\mathrm{PaO} 2 / \mathrm{FiO} 2$ ratio. Crit. Care 2008;12(1):407-409. Doi: 10.1186/cc6777 